\title{
Looking for land allocations for poplar in rural areas considering optimization and protection of natural resources usage
}

\author{
*Adam Czarnecki, **Jerzy Jonczak \\ *Nicolas Copernicus University, Laboratory of Landscape Planning and Ecology, \\ Gagarina 9, 87-100 Toruń, Poland \\ e-mail: czarn@biol.uni.torun.pl \\ **Pomeranian University in Stupsk, Department of Geomorphology and Quaternary Geology, \\ Partyzantów 27, 76-200 Słupsk, Poland
}

\begin{abstract}
The paper is a case-study of the possibilities for poplar introduction into rural landscape based on the example of Grodziczno commune area. The ultimate outcome of the study are maps, which indicate areas where farmers can consider introduction of poplar cultivation as an adequate response to external conditions, such as prices and demand for food products and regulations, as well as internal conditions - input for production, soil, water, landscape values protection and for overall improving of farm performance in terms of sustainability.
\end{abstract}

Key words: poplar, rural landscape, landscape protection, biomass.

\section{Introduction}

Human needs are satisfied by consumption of a wide range of products. Each of them is produced from natural resources transformed by proper technology. Some of them are produced in a natural way as ecosystem services. Irrespective of the production character, all systems of production require some energy input. Apart from solar energy, the ecosystems under human control require an additional input of energy provided by men. In the past, the renewable energy was mainly supplied by human activity. During the last centuries, those renewable sources of energy have been gradually replaced by easily operated nonrenewable sources. Consequently, nowadays we face environmental problems due to air pollution with $\mathrm{CO}_{2}$.

So we have to look for other sources of energy among renewable ones. Biomass is one of the most promising among them. New crops for biomass yielding are consid- ered within trees and herb species characterized by prompt yearly increase of biomass. Long-term plantations are considered most convenient for farm requirements. Allocation for biomass plantation in arable land meets overproduction of traditional crop. Modern technology limiting the arable land in rural areas gives the space for industrial and other crops. Nevertheless temporary exclusion of an arable land from production is not in line with sustainable development, because it requires fallowing subsidies. Traditional afforestation takes away benefits in the long run. Trees plantations can provide a new crop for local and external use. So agroforestry by combining traditional crops with wood plantation would enable a sustainable agriculture. Deep rooted long-term tree plantations with internal important matter turnover can protect and improve farm functioning. The growing demand for biomass and timber helps to utilize the production surplus. In Europe the consumption of timber and biomass is 0.8 cubic meter 
per capita, in Poland 0.55 and in both cases the tendency is growing (Paschalis 1997). Using one's own energy in farming for heating and electricity provides the chance to develop a system less dependent on external nonrenewable sources. For environmental problems restoring forestry in farms supports the effort to internalize all processes connected with matter turnover. Broad-leaved tree species are right for farm production. Among species whose biomass increases immediately after sprouting, one can mention willow and poplar. Some studies show that the poplar has a positive impact on soil fertility (Dziadowiec et al. 2007, 2008; Jonczak 2009) and quality of humus (Gonet et al. 2009). It does not change the soil properties in terms of typical farm production. However, since it is a rather extensive cultivation, characterised by fast internal matter turnover, it may contribute to the enrichment of soil with organic matter. This seems important for arable fields, where annual plants had been intensively cultivated for many years and most of the produced biomass had been removed. Poplar as a crop is traditionally cultivated in France, Belgium, Italy or The Netherlands. Nowadays, there is a growing application of that tree in UK and Germany. Poplar plantations are formed by fast growing trees, so they are able to provide a farm with timber and biomass contributing to elasticity of its economics.

Since the main goal of farm is food production we can consider multiple functions of poplar cultivation according to ground characteristics, as well as water and matter flows within a landscape. Rural areas in a postglacial landscape create a diversity of habitats characterized by different soil and water conditions. Therefore it is possible to apply different crops, the most suitable for specific conditions, justified on the grounds of market demands and prices. However, considering different characteristics of particular crops - annual or permanent, deep- or shallow-rooted etc. - it is possible to optimize the management of rural areas, not only in economic but also in environmental terms. Consequently energetic crops can represent a good alternative for conventional farms, as well as they can be usefully combined in farms with conventional crops. The ability to consider different functions and usefulness of energetic crops on a farm as an agroforestry system is a potential way to solve at the same time some of the main threats of the modern world, for example provision of energy, timber, development of rural areas and to stop environmental problems on a local and global scale. Poplar cultivation, which produces timber and biomass within 10-25 years, would mainly be established on sites of potential medium productivity and on fragile ones, and also in a landscape previously deprived of trees since, combining an economic and environmental function, would be a good chance for a sustainable farm. This kind of production combined with a proper management of soil and water enables a multifunctional use of rural areas.
The aim of this paper is to suggest a possible localization for poplar plantations, taking into account the needs of this tree species, as well as the needs of farmers.

\section{Materials and methods}

The studies were conducted in Grodziczno commune area. The total study area was $154.2 \mathrm{~km}^{2}$, including $21.9 \mathrm{~km}^{2}$ covered with forests, mainly coniferous ones $(14.2 \%$ of the whole area). The major part of the area is an arable land dominated by traditional crops in spite of high diversification of soil conditions. One of the main commune politics is to increase the forestry area. Some of the arable lands are considered to be afforested, mainly those actually excluded from agriculture because of a low margin. Poplar plantations enable farmers to adapt in a more flexible way to market fluctuations, solving at the same time other issues, so they meet farmer needs more adequately than traditional forest. They can be introduced for all lands, including the low productivity ones. As emphasized above, in order to make the right decision when replacing traditional crops by a poplar plantation, we have to consider soil characteristics, as well as farmer needs. To facilitate the decision, a new type of agricultural land valuation was proposed, which combines a traditional system of land quality assessment with socioeconomic and environmental characteristics of farms. It seems useful for decision-making regarding the division of lands allocated for traditional and new crops in a way that it optimally combines environmental and economic benefits. As a permanent crop, poplar can substantially decrease the ratio of erosion and the losses of input for production if planted on the margins. Moreover, it can use nutrients inaccessible for traditional crops due to deeper roots that enable the plant to overcome obstacles in the soil represented by stones and to reach deep underground water. For these reasons, poplar significantly differs as compared with traditional crops. Therefore, a different approach to the assessment of soil sites has to match traditional soil information with added description of relief, as well as hydrology and landscape features. When processing this information in order to plan out the allocation of an arable land for poplar stands, it is possible to combine four criteria: to increase efficiency of an input for production, to diversify a landscape in order to counteract soil water and wind erosion, to reduce an input for production and to stabilize the latter according to market fluctuation. The outcomes are grids within soil classes that display a range of characteristics and issue to be solved with advantage by introducing different types of poplar stands. 


\section{Results and discussion}

Cartographic data analysis and field studies show a high diversity of soil quality in Grodziczno commune area (Table 1). This results from spatial differentiation of superficial deposits and relief, whose variability leads to heterogeneity of hydrological conditions. Water resources are the most important factor for planning the poplar plantations. Water uptake by a poplar is about 200-500 mm during a growing season. Meiressone et al. (1999) estimated a water uptake by a plantation of Populus trichocarpa and Populus deltoides at $320 \mathrm{~mm}$, Black et al. (1996) - at $400 \mathrm{~mm}$ for Populus tremuloides. Liu et al. (1988) and Hinckley et al. (1994) reported extreme values: $128 \mathrm{~mm}$ (Populus deltoides) and $550 \mathrm{~mm}$ (Populus trichocarpa and Populus deltoides), respectively. According to the above criteria, it was possible to identify the area with suitable site conditions for poplar introduction (Fig. 1).

The area which meets the criteria for introduction of poplar plantations ranges from over $154 \mathrm{~km}^{2}$ to $103.3 \mathrm{~km}^{2}$, that is $66.9 \%$ of commune area. Nevertheless, the selected area is spatially differentiated in respect of arable soil qual-

Table 1. Usefulness of different soil complexes for poplar plantation in Grodziczno commune area

\begin{tabular}{|c|r|r|r|r|}
\hline \multirow{2}{*}{$\begin{array}{c}\text { Soil } \\
\text { complexes }\end{array}$} & \multicolumn{2}{|c|}{$\begin{array}{c}\text { Total area of soil } \\
\text { complexes }\end{array}$} & \multicolumn{2}{c|}{$\begin{array}{c}\text { Land suitability for } \\
\text { poplar plantation }\end{array}$} \\
\cline { 2 - 5 } & ha & \multicolumn{1}{c|}{$\%$} & \multicolumn{1}{c|}{ ha } & $\%$ \\
\hline 2 & 826 & 5.4 & 776 & 5.00 \\
\hline 3 & 583 & 3.8 & 474 & 3.10 \\
\hline 4 & 1,855 & 12.0 & 1,782 & 11.60 \\
\hline 5 & 4,166 & 27.0 & 3,597 & 23.30 \\
\hline 6 & 2,878 & 18.7 & 1,774 & 11.50 \\
\hline 7 & 1,540 & 10.0 & 532 & 3.50 \\
\hline 9 & 7 & 0.0 & 3 & 0.02 \\
\hline $2 z$ & 634 & 4.1 & 477 & 3.10 \\
\hline $3 z$ & 836 & 5.4 & 537 & 3.50 \\
\hline wastelands & 86 & 0.6 & 45 & 0.30 \\
\hline forest soils & 2,006 & 13.0 & 333 & 2.20 \\
\hline TOTAL & 15,417 & 100.0 & 10,330 & 66.90 \\
\hline
\end{tabular}

ity (Table 1, Fig. 2). A considerable part of the area is located on soils of good quality, which developed from moraine clay. These soils should be cultivated. Afforestation is possible in places where soils are endangered by certain factors - for example erosion. In these cases, afforestation would have a protective effect.

Among soils of good quality, there are some parts with less fertile soils - complexes 7, 9 and 3z. Afforestation of these soils is a good solution (Fig. 3). Introduction of poplar on these areas can cause an increase of the afforestation rate from about $7 \%$ to $22 \%$. There is also possible forestation of soil complex 6, but in a second order (Fig. 3). Afforestation of wastelands, which are defined as forest soils, is the most desirable and urgent. These soils have extremely unfavorable conditions for cultivation, but some of them have good site conditions for poplar production. Their total area is 2006 ha. Nowadays, it is not afforested an area of about 378 ha (Table 1). Introduction of the poplar in such places can play several functions - for example biomass production and the protection of natural resources (soil, water). A marginal exploitation of agricultural soils can cause a significant increase of landscape diversity (Fig. 3) and a more effective utilization of natural resources.

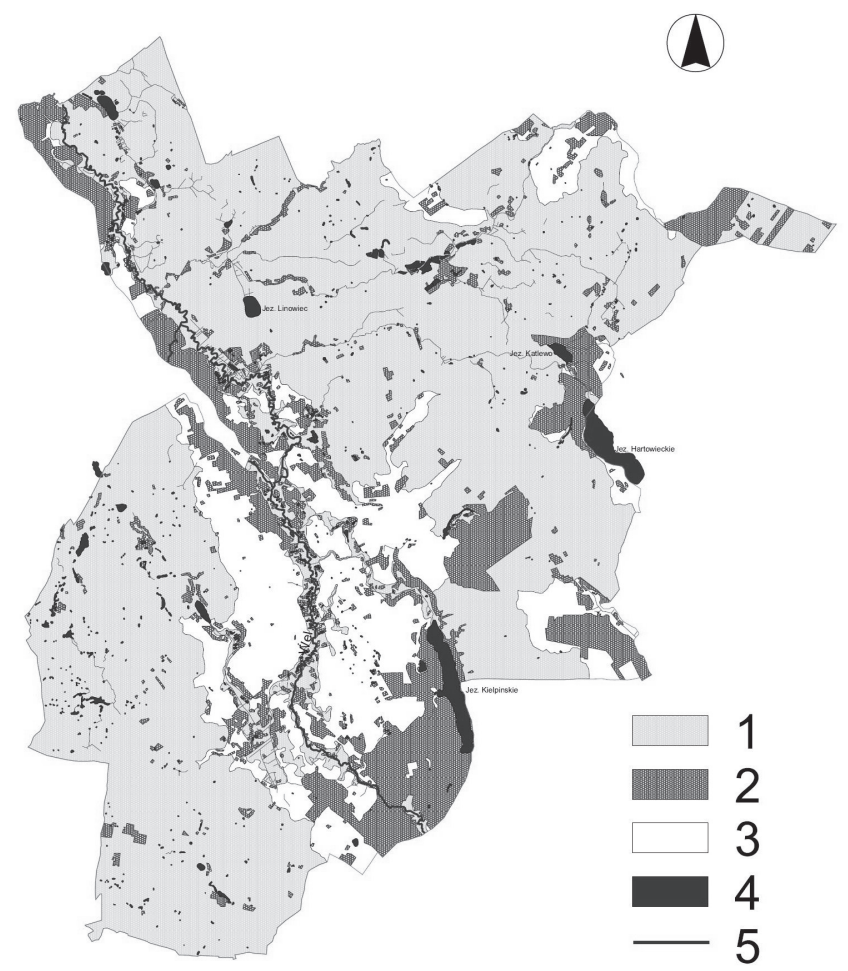

Figure 1. Land suitability for poplar plantation in Grodziczno commune area ( 1 - suitable; 2 -forests; 3 - low suitability; 4 - lakes; 5 - rivers) 

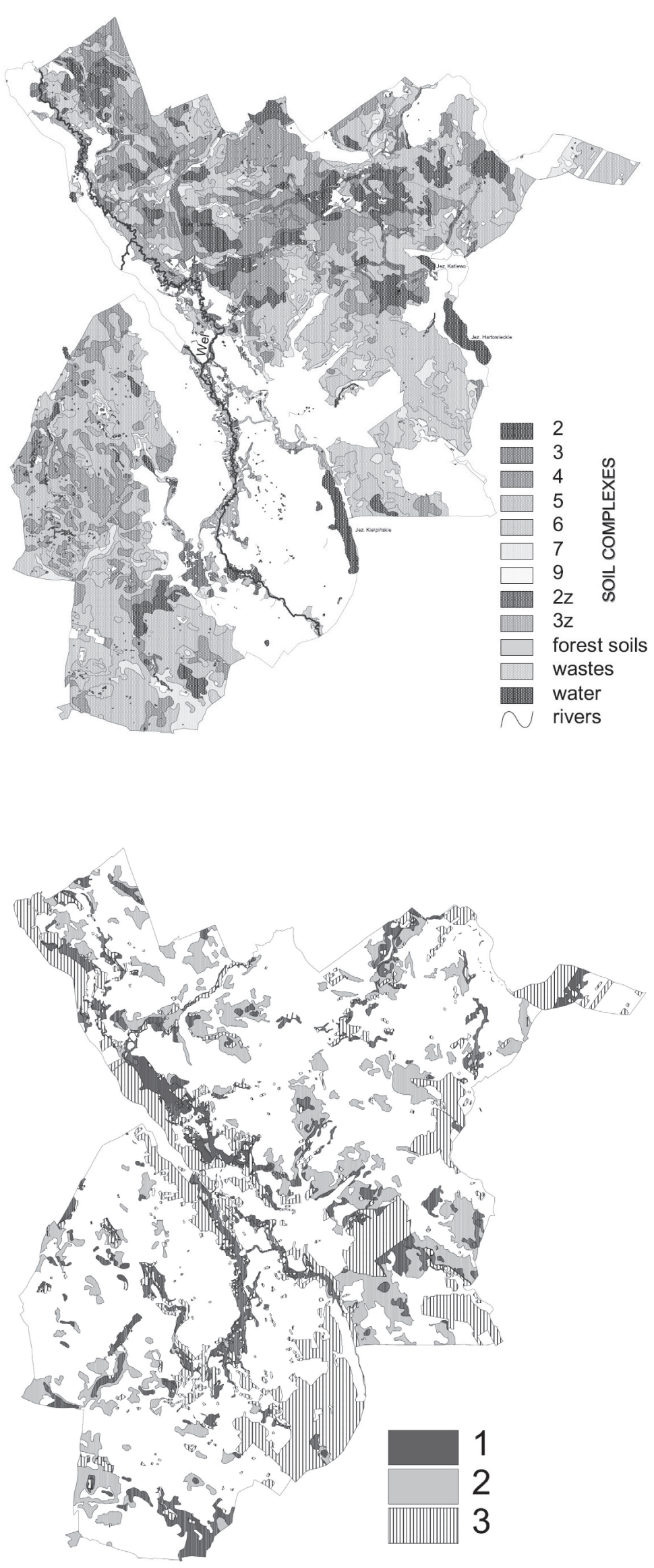

Figure 2. Soil quality in the area suitable for poplar introduction
Figure 3. Potential poplar locations (1 - wastes, forest soils and weakest arable soils; 2 - soils for forestation in second order - complex 6;3- existing forests) 


\section{Conclusions}

This study showed that there is a large potential for biomass production in rural areas. Site conditions in two thirds of the Grodziczno commune area meet the criteria for poplar cultivations (as one of the possible biomass crops). Since the major part of that area has soils of good quality, the basic function of the area should be crop production. Poplar, or other biomass cultivations should be introduced in a second order - for example when some parts of these areas are endangered by erosion or other factors, or when crop production is not possible (for example due to heavy metals pollution). In case of soil erosion risk, a recommended form of afforestation is a multi-line tree belt at lower altitudes. Due to large relief differentiation in the commune of Grodziczno, among areas with good soils developed from moraine, there are some areas with less fertile soils where crop production is unprofitable. Some of these areas are already excluded from the agricultural crop, so they have good site conditions for poplar introduction (about $7 \%$ of the total commune area). Biomass production can be a good solution for these areas. Our analysis indicated the importance of the management of wastelands and forest soils (at present not afforested) - corresponding to about $3 \%$ of the commune area. This study showed also that biomass production can take place on the least fertile soils bringing them into cultivation. In a commune scale, it is a huge potential - about $10 \%$. Extensive afforestation can improve a farmer's situation in the long run. Proper distribution of poplar cultivations in a rural landscape can contribute to its protection and differentiation, and can have a crucial role in soil and water protection.

\section{References}

Black T. A., den Hartog G., Neumann H. H., Blanken P. D., Yang P. C., Russel C., Nesic Z., Lee X., Chen S. G., Staebler R. \& Novak M. D., 1996, Annual cycles of water vapour and $\mathrm{CO}_{2}$ fluxes in and above a boreal aspen forest, Global Change Biology 2(3): 219-229.
Dziadowiec H., Jonczak J., Czarnecki A. \& Kacprowicz K., 2007, Mass, dynamics and chemical composition of litter fall in age differentiated plantations of poplar clone Hybrid 275, Roczniki Gleboznawcze 58 (3/4): 68-77.

Dziadowiec H., Jonczak J., Czarnecki A. \& Kacprowicz K., 2008, Comparison of plant litter fall in two poplar plantations of Hybryd 275 and Robusta, Roczniki Gleboznawcze 59(1): 69-76.

Gonet S. S., Dębska B., Banach-Szott M., Dziamski P. \& Miatkowski Z., 2009, Influence of poplar plantations on the properties of soil humic acids, Roczniki Gleboznawcze 60(1): 39-44.

Hinckley T. M., Brooks J. R., Cermak J., Ceulemans R., Kucera J., Meinzer F. C., \& Roberts D. A., 1994, Water flux in a hybrid poplar stand, Tree Physiology 14: 1005-1018.

Jonczak J., 2009, Leaf litter fall decomposition in age-differentiated stands of poplar clone Hybrid 275, Polish Journal of Soil Science XLII(2): 159-167.

Liu Z., Zheng S. \& Zhang D., 1988, A study on the relationship between water supply and growth in poplar plantation, FAO/IPC Meeting, Session XXVIII, Beijing, P. Rep of China.

Meiressone L., Nadezhdin N., Cermak J., Van Slycken J. \& Ceulemans R., 1999, Measured sap flow and simulated transpiration from a poplar stand in Flanders (Belgium), Agricultural and Forest Meteorology 96: 165-179.

Paschalis P., 1997, Poziom i kierunki zużycia drewna w Polsce oraz w krajach Unii Europejskiej. Stan obecny i perspektywy [The level and trends in wood use in Poland and the European Union countries - the state and perspectives], Sylwan 10/1997: 5-19. 